\title{
Clear Cell Carcinoma on an Endometriotic Nodule of The Recto-Vaginal
}

\section{Septum: Case Report}

\section{Leyre Pegenaute | María Cuadra | Inaki Lete*}

\section{*Correspondence: Inaki Lete}

Address: Gynaecological Oncology Unit. Obstetrics and Gynaecology Clinical Management Unit. Araba University Hospital, Vitoria, Spain

e-mail $\bowtie$ : luisignacio.letelasa@osakidetza.net

Received: 29 January 2021; Accepted: 04 February 2021

Copyright: (C) 2021 Pegenaute L. This is an open-access article distributed under the terms of the Creative Commons Attribution License, which permits unrestricted use, distribution, and reproduction in any medium, provided that the original work is properly cited.

\section{ABSTRACT}

Endometriosis is a benign disease that can rarely become malignant. In this case report we present the case of a 50 -yearold woman with clear cell carcinoma arising from an endometriotic nodule of the rectovaginal septum and discuss about the clinic, difficulty for diagnosis, evolution and treatment of the disease. The published data on this strange location of clear cell carcinoma, its etiopathogenesis and the risk factors for the malignancy of an endometriotic nodule are analysed. We conclude despite its low incidence, the malignancy of RVS nodule of extra-ovarian endometriosis is possible and should be considered when a cystic or solid-cystic lesion appears in the pelvis in a woman with a long history of endometriosis.

Keywords: Endometriosis, Rectovaginal Septum, Malignancy, Clear Cell Carcinoma

\section{Introduction}

Endometriosis is defined as the presence of endometrial tissue, glands and stroma, outside the uterine cavity. It is a disease that affects $2-10 \%$ of the general population, $50 \%$ of patients who consult for infertility and up to $60 \%$ of patients with chronic pelvic pain (Giudice and Kao, 2004).

Endometriosis has been associated with a slight increase in non-gynaecological cancers (Saavalainen et al., 2018a) and some gynaecological cancers, especially endometrioid and clear cell carcinoma of the ovary (Saavalainen et al., 2018b). Malignancy of endometriotic cysts and / or implants has also been described (Gadducci and Zannoni, 2020).

The incidence of malignancy is around $1 \%$ of patients with endometriosis and the most frequent location is in the ovaries, $75-80 \%$ of cases, while in the other $20-25 \%$ the location is extraovarian, thus being a rare finding (Gadducci and Zannoni, 2020). The most frequent histological types are endometrioid carcinomas, sarcoma and clear cell carcinoma (Mandai et al., 2009). Due to the low 
incidence of extra-ovarian cases and the limited literature on the matter, there are no clear criteria on their management.

The objective of this publication is to present a case of extraovarian endometriosis malignancy, in a clear cell carcinoma, in a woman with known endometriosis, in the rectovaginal septum (RVS).

\section{Case Description}

This is a 50-year-old woman, who is referred to the Gynaecological Oncology Unit, from General Gynaecology, for presenting a clear cell carcinoma on an endometriosis implant in Douglas.

MH: medical history of the patient: Nuligesta, diagnosed with an endometriotic nodule of the RVS of $5 \times 4 \mathrm{~cm}$ in 1999, on treatment with oral contraceptives in a cyclical pattern since then, who went to the emergency room in September 2019, due to abdominal pain, along with nausea and vomiting. Since 1999, the year in which RVS endometriosis was diagnosed, no gynaecological controls have been performed. In the exploration performed in the Emergency Department, a $5 \mathrm{~cm}$ posterior vaginal cul-desac outgrowth is visualized, of a hard, fixed consistency, and a non-painful solid tumour is palpated on the posterior wall of the vagina in the rectovaginal septum of about $5 \times 4 \mathrm{~cm}$. In the transvaginal ultrasound a rounded formation measuring 70x54 mm with an isoechoic appearance was observed at the retrouterine level with some areas of greater echo density. No other findings of interest were seen.

Ibuprofen treatment was prescribed and he was referred to the general gynaecology consultation. Magnetic resonance imaging (MRI) was performed with these findings.:

Uterus showing an intramural myoma on the right edge measuring $2.5 \times 2.2 \times 2.3 \mathrm{~cm}$ and another pedunculated on the left edge measuring $5.7 \times 3 \times 3.5 \mathrm{~cm}$. At the retrouterine level and occupying the cul-de-sac of Douglas, a mass closely related to the posterior wall of the uterine isthmus with welldefined edges and a heterogeneous signal measuring $3.8 \times 5 \times 5 \mathrm{~cm}$ is identified. The tumour is suggestive of pedunculated myoma with cystic-haemorrhagic degeneration. Rest of structures included in the study without valuable pathological findings.

Given these findings, discontinuing contraceptive treatment and observation with new monitoring in 6 months was recommended. Six months later the patient was in amenorrhea and an ultrasound was repeated, showing in Douglas a solid-cystic image of $7.5 \times 6 \mathrm{~cm}$, with dense content and a solid component with low resistance central vascularization. On suspicion of malignancy a computerized axial tomography (CT) was requested with similar findings to those of the MRI (Fig. 1). 


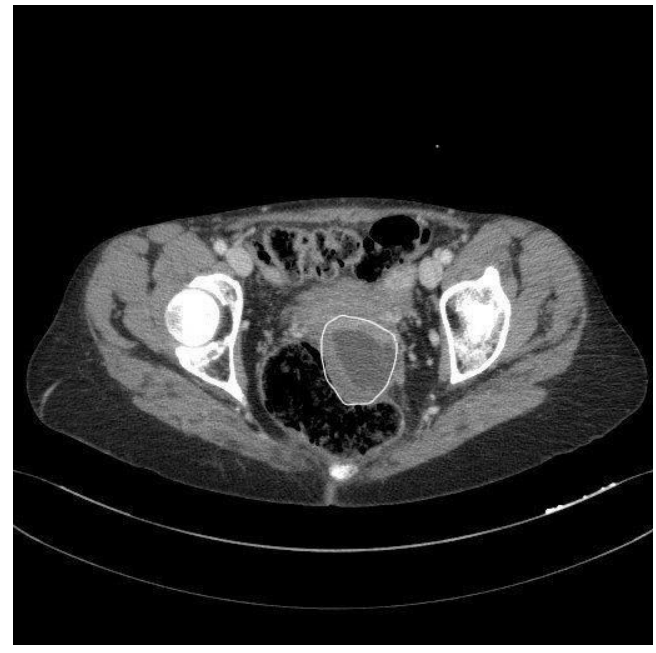

Figure 1: Pelvic CT. Highlighted image on the anterior wall of the rectosigma corresponding to the clear cell tumour

Tumoral markers were the following: Ca 125: $4.5 \mathrm{U} / \mathrm{mL}$, Ca 19.9: $23 \mathrm{U} / \mathrm{mL}, \mathrm{He} 4: 23$ pmol/L. ROMA index: low risk $(1,2 \%)$.

With the suspected diagnosis of pedunculated myoma with degeneration, a surgical intervention was decided to perform a hysterectomy and double adnexectomy by a general gynaecology team.

\section{Surgery on 09/17/2020}

Findings: Uterus of normal size, with intramural myoma on the right uterine edge of $2 \mathrm{~cm}$ and pedunculated myoma on the left edge of $3 \mathrm{~cm}$. A soft mass of about $5 \mathrm{~cm}$ is palpated, but not seen, which is covered by rectosigma and is firmly attached to the uterine isthmus.

Surgery: Pfannenstiel incision. During the detachment of the rectum the spontaneous opening of the mass occurs, leaving cerebroid content to the peritoneal cavity. This tissue was analysed by frozen section and informed as suspicion of malignancy without being able to define histological origin. Subsequently, a hysterectomy and double adnexectomy were performed.

Pathological findings were the following:

a) Sent as "mass content in Douglas" (intraoperative biopsy): carcinoma morphologically and immunophenotypically compatible with clear cell carcinoma.

b) Uterus, Fallopian tubes and ovaries: focus of carcinoma morphologically and immunophenotypically compatible with clear cell carcinoma: size: 0.8 x $0.3 \mathrm{~cm}$, location on the surface of the posterior side of the cervix, in contact with surgical margin, penetrating $0.3 \mathrm{~cm}$ into the posterior cervical wall. Immunohistochemical study: pax $8+$, napsin a + , wt1-, non-aberrant expression of $\mathrm{p} 53$. 
With these results the patient is presented to the Tumour Committee in which it is decided to stage the disease, for which a new surgical intervention is scheduled to be performed on October 23, 2020:

Findings were the following: Peritoneal Cancer Index (PCI): 0

Surgical procedure performed: Intraoperative biopsies of the anterior wall of the rectosigma and pelvic and para-aortic lymphadenectomy, and radical omentectomy.

Pathological findings were the following:

Intraoperative biopsies performed in the anterior wall of the rectum and RVS were all negative for malignant cells. Lymph nodes from lymphadenectomies of the right pelvis and para-aortic region were also negative. In the left pelvic lymphadenectomy, nine lymph nodes were identified, two of them with infiltration by carcinoma $(2+/ 9)$.

With these results, the diagnosis of clear cell carcinoma on an endometriosis focus in the rectovaginal septum stage IIIA1 was established and the Tumour Committee decided to refer to Medical Oncology for adjuvant chemotherapy treatment. The patient is currently receiving carboplatin + paclitaxel.

\section{Discussion}

Malignant transformation of endometriosis is estimated to occur in around $0.7-1.6 \%$ of patients with the disease (Tarumi et al., 2015). There are some criteria defined by Sampson and Scott (Sampson, 1925; Scott, 1953) to consider the endometriosis nodule to be malignant: (i) Finding of benign and malignant endometrial tissue in the tumour; (ii) Histology of the neoplasm compatible with an endometrial origin; (iii) Failure to identify another primary tumour; (iv) Demonstration of a dysplastic phase between benign endometriosis and carcinoma. In our case, the first three criteria were met. Regarding the fourth criterion for demonstration of dysplasia, the transition zone between benign and malignant endometrium is only detected in 36-42\% of cases (Mostoufizadeh and Scully, 1980). In our patient, this dysplastic phenomenon could not be demonstrated in the pathological examination of the surgical piece.

As in the development and persistence of endometriosis, hormonal factors seem to play an important role in the process of malignancy (Reimnitz et al., 1988). In the series by Modessit, et al. (2002), of the 21 patients with carcinomas associated with endometriosis of extraovarian location, 14 patients $(62 \%)$ received replacement therapy with oestrogens. Our patient had a long evolution of 
endometriosis, of at least 20 years and had been on treatment with combined oral contraceptives.

Current theories about the origin of endometriosis include genetic and epigenetic factors (Koninckx et al., 2019). Among the environmental factors capable of inducing genetic modifications, one of the most recognized is dioxins (Koninckx et al., 1994). Since, in the process of some textile productions, such as during the manufacture of vaginal tampons, dioxins are released that can contaminate the product, it has been suggested that the habitual use of tampons that rest on the posterior vaginal fornix, close to the rectovaginal septum, could be a factor that favours the malignancy of an endometriotic nodule at this level (Modesitt et al., 2002). Our case is a clear cell carcinoma developed over an endometriosis focus of the rectovaginal septum. Despite theories about the possible impact of dioxins on the rectovaginal septum, the rectovaginal septum is an uncommon site for the development of this type of cancer. In the review by Irvin et al. in 1998, they identified 222 cases of extraovarian endometriosis malignancy, of which only 9 cases $(4 \%)$ corresponded to nodules of the rectovaginal septum (Irvin et al., 1998).

The symptoms that accompany a malignant endometriotic tumour are variable, but the most frequently reported symptom is abdominal or pelvic pain (up to $51 \%$ of patients) (Benoit et al., 2006). In the case that we present, the patient went to the emergency department of our hospital due to abdominal pain accompanied by nausea and vomiting.

Among the histological types of malignant tumours associated with extraovarian endometriosis, 90\% correspond to endometrioid tumours and only 5\% to clear cell tumours (Brunson et al., 1988), while in cases of malignant ovarian endometrioma the clear cell tumour is more prevalent (Scully et al., 1998).

It has been suggested that a long history of endometriosis may constitute a predominant risk factor in the malignancy of the disease (Nezhat et al., 2014). In a recent series of 10 cases of patients with extra-ovarian malignant endometriosis, 6 of the 10 patients (60\%) had a long history of endometriosis and were also nulliparous (Poon and Rome, 2020). Our patient met both requirements: she had a history of at least 20 years of evolution of endometriosis and was nulliparous.

Malignant tumours associated with extra-ovarian endometriosis are usually limited to the pelvis. A recent study that analysed a Japanese database of endometriosis-associated cancers found 11 cases of carcinoma in the RVS among 1,397 rare or atypical locations of the disease, and none had an extension outside the pelvis (Mandai et al., 2020). In our case, the patient had two pelvic lymph nodes metastasized due to the neoplasia, but she did not present disease in the upper abdomen. 


\section{Conclusion}

Despite its low incidence, the malignancy of RVS nodule of extra-ovarian endometriosis is possible and should be considered when a cystic or solid-cystic lesion appears in the pelvis in a woman with a long history of endometriosis.

\section{References}

Benoit L, Arnould L, Cheynel N, Diane B, Causeret S, Machado A, Collin F, Fraisse J, Cuisenier J. Malignant extraovarian endometriosis: a review. EurJ Surg Oncol 2006; 32: 6-11.

Brunson GL, Barclay DL, Sanders M, Araoz CA. Malignant extraovarian endometriosis: two case reports and review of the literature. Gynecol Oncol 1988; 30: 123-130.

Gadducci A and Zannoni GF. Endometriosis-associated Extraovarian Malignancies: A Challenging Question for the Clinician and the Pathologist. Anticancer Res 2020; 40: 2429-2438.

Giudice LC and Kao LC. Endometriosis. The Lancet 2004; 364: 1789-1799.

Irvin W, Pelkey T, Rice L. Endometrial stromal sarcoma of the vulva arising in extraovarian endometriosis: a case report and literature review. Gynecol Oncol 1998; 71: 313-316.

Koninckx PR, Braet P, Kennedy SH, Barlow DH. Dioxin pollution and endometriosis in Belgium. Hum Reprod 1994; 9: 1001-1002.

Koninckx PR, Ussia A, Adamyan L, Wattiez A, Gomel V, Martin DC. Pathogenesis of endometriosis: the genetic/epigenetic theory. Fertil Steril 2019; 111: 327-340.

Mandai M, Osuga Y, Hirata T, Enomoto T, Nakai H, Honda R, Taniguchi F, Katabuchi H. Cancers associated with extraovarian endometriosis at less common/rare sites: A nationwide survey in Japan. J Obstet Gynaecol Res 2020; 46: 917-923.

Mandai M, Yamaguchi K, Matsumura N, Baba T, Konishi I. Ovarian cancer in endometriosis: molecular biology, pathology, and clinical management. Int J Clin Oncol 2009; 14: 383-391.

Modesitt SC, Tortolero-Luna G, Robinson JB, Gershenson DM, Wolf JK. Ovarian and extraovarian endometriosisassociated cancer. Obstet Gynecol 2002; 100: 788-795.

Mostoufizadeh M and Scully RE. Malignant tumors arising in endometriosis. Clin Obstet Gynecol 1980; 23: $951-963$.

Nezhat F, Apostol R, Mahmoud M, el Daouk M. Malignant transformation of endometriosis and its clinical significance. Fertil Steril 2014; 102: 342-344.

Poon C and Rome R. Malignant extra-ovarian endometriosis: A case series of ten patients and review of the literature. Austral N Z J Obstet Gynaecol 2020; 60: 585-591.

Reimnitz C, Brand E, Nieberg RK, Hacker NF. Malignancy arising in endometriosis associated with unopposed estrogen replacement. Obstet Gynecol 1988; 71: 444-447.

Saavalainen L, Lassus H, But A, Tiitinen A, Härkki P, Gissler M, Heikinheimo O, Pukkala E. A Nationwide Cohort Study on the risk of non-gynecological cancers in women with surgically verified endometriosis. Int J Cancer 2018; 143: $2725-2731$.

Saavalainen L, Lassus H, But A, Tiitinen A, Härkki P, Gissler M, Pukkala E, Heikinheimo. Risk of gynecologic cancer 
Case Report

DOI: http://dx.doi.org/10.47746/FMCR.2021.2106

according to the type of endometriosis. Obstet Gynecol 2018; 131: 1095-1102.

Sampson JA. Endometrial carcinoma of the ovary, arising in endometrial tissue in that organ. Archiv Surg 1925; 10: 1-72.

Scott RB. Malignant changes in endometriosis. Obstet Gynecol 1953; 2: 283-289.

Scully RE, Young RH, Clement PB. Tumors of the ovary, maldeveloped gonads, fallopian tube, and broad ligament. In: Armed Forces Institute of Pathology 1998. Atlas of tumor pathology, fascicle 23. 3rd series. Bethesda 1998; pp: 94-97.

Tarumi Y, Mori T, Kusuki I, Ito F, Kitawaki J. Endometrioid adenocarcinoma arising from deep infiltrating endometriosis involving the bladder: A case report and review of the literature. Gynecol Oncol Rep 2015; 13: 68-70. 